\title{
Rhabdomyolysis and acute encephalopathy in late onset medium chain acyl-CoA dehydrogenase deficiency
}

\author{
W Ruitenbeek, P J E Poels, D M Turnbull, B Garavaglia, R A Chalmers, R W Taylor, \\ F J M Gabreëls
}

\begin{abstract}
A previously asymptomatic 30 year old man presented with rhabdomyolysis, muscle weakness, and acute encephalopathy after strenuous exertion in the cold without adequate food intake. Serum and muscle carnitine concentrations were decreased. Urinary excretion of carnitine and glycine esters and biochemical examination of skeletal muscle and fibroblasts led to the diagnosis of medium chain acyl-CoA dehydrogenase (MCAD) deficiency. A point mutation at nucleotide position 985 of the coding region of the MCAD gene was found. The MCAD protein was synthesised in the patient's fibroblasts at a normal rate, but was unstable. In general, patients in whom the 985 point mutation has been established show much more severe clinical symptoms and other symptoms than those seen in this patient. The relation of the 985 point mutation and the residual MCAD activity to the symptoms is not as straightforward as previously thought.
\end{abstract}

(F Neurol Neurosurg Psychiatry 1995;58:209-214)

Keywords: rhabdomyolysis; medium chain acyl-CoA dehydrogenase deficiency; encephalopathy

University Hospital

Nijmegen, The Netherlands

Institute of Pediatrics W Ruitenbeek

Institute of Neurology

P J E Poels

F J M Gabreëls

School of

Neurosciences,

University of

Newcastle, UK

D M Turnbull

$\mathrm{R}$ W Taylor

National Institute of Neurology "C Besta", Milan, Italy

B Garavaglia

St George's Hospital Medical School, University of London, UK

R A Chalmers

Correspondence to:

Dr W Ruitenbeek

Department of Pediatrics,

University Hospital

Nijersity Hospital 9101 ,

Nijmegen, PO Box 9101,

The Netherlands.

Received 2 August 1994

Accepted 9 September 1994
Rhabdomyolysis (acute muscle necrosis) can be due to various acquired or hereditary causes. $^{12}$ The hereditary causes include specific defects of metabolism-for example, enzyme defects in glycogen catabolism and glycolysis. ${ }^{3}$ Of the disorders of muscle lipid metabolism, carnitine palmitoyltransferase deficiency is one of the most common metabolic causes of rhabdomyolysis. ${ }^{4}$ Recurrent attacks of rhabdomyolysis have been found in three patients reported to have myopathic carnitine deficiency..$^{5-7}$ Recently a few other defects of fatty acid oxidation have been associated with rhabdomyolysis. ${ }^{8-10}$

Medium chain acyl-CoA dehydrogenase (MCAD) deficiency is thought to be the most common disorder of fatty acid oxidation..$^{1-14}$ As an inborn error of metabolism it has been recognised with increasing frequency in children with a Reye-like syndrome. As a consequence of the disturbance in fatty acid oxidation, MCAD deficiency is associated with acute attacks of hypoketotic hypoglycaemia and $\mathrm{C}_{6}-\mathrm{C}_{10}$ dicarboxylic aciduria. The attacks are provoked by stress, fever, viral illness, and fasting. Some patients, earlier classified as having carnitine deficiency, later seemed to have MCAD deficiency. ${ }^{13}$ In urine a characteristic profile of $\mathrm{C}_{6}-\mathrm{C}_{10}$ acylcarnitines can usually be shown, as well as acylglycines (for example, suberylglycine). The presence of octanoylcarnitine in plasma may be a specific indication for MCAD deficiency. ${ }^{15}$

The age of initial presentation of MCAD deficiency varies widely. Most patients present acutely, usually between infancy and the second year of life. Duran et al described an asymptomatic adult man. ${ }^{16}$

Recent DNA studies have shown a high prevalence of a point mutation at nucleotide position 985 of the coding region of the MCAD gene in patients deficient in MCAD. ${ }^{17}$

Here we describe the first patient with an initial clinical presentation of rhabdomyolysis and acute encephalopathy in adult life, who was later proved to have MCAD deficiency, established both at the enzyme and DNA level.

\section{Case history}

A 30 year old man developed progressive muscle weakness in his arms and legs after a day of strenuous exercise in the cold without taking any food. He complained of headache and nausea, began vomiting, and produced dark brown coloured urine. At the end of the day he became lethargic, irritable, and agitated. He was admitted with lowered consciousness. He had had another episode of vomiting, headache, and motor restlessness one year before. This occurred during a long motorbike trip during which he did not eat. It was said that he sometimes had an acetonelike breath, especially when he had not eaten. The family history was non-contributory.

On admission the patient was delirious. Blood pressure, pulse rate, and temperature were normal. Due to generalised muscle weakness, he was unable to stand upright. Muscle stretch reflexes were normal and symmetric. His liver was not enlarged. There was no focal neurological deficit. On admission creatine kinase activity in serum was 4000 IU/l (normal range 15-91 IU/l) and myoglobin was $134 \mu \mathrm{g} / 1$ (normal $<85 \mu \mathrm{g} / \mathrm{l})$. The calcium concentration of $2.20 \mathrm{mmol} / 1$ was low normal (normal range $2 \cdot 20-2 \cdot 60$ ). Phosphate concentrations were increased to $1.70 \mathrm{mmol} / 1$ (normal range $0 \cdot 76-1 \cdot 24$ ). Blood glucose was normal. Activity of transaminases in serum was raised, whereas $\gamma$-glutamyltransferase activity was normal. Potassium concentration was increased to $5.8 \mathrm{mmol} / 1$ (normal range 
3.3-4.4 mmol/1). The patient had a low urinary output for two days $(500 \mathrm{ml}$ per 24 hours). A transient increase of plasma urea to $26 \mathrm{mmol} / 1$ (normal range $3 \cdot 1-7 \cdot 5 \mathrm{mmol} / \mathrm{l}$ ) and creatinine to $193 \mu \mathrm{mol} / 1$ (normal range $70-106 \mu \mathrm{mol} / \mathrm{l}$ ) indicated a moderate renal insufficiency. The protein and ketone body reaction in urine was slightly positive.

Protein in CSF was slightly increased (530 $\mathrm{mg} / \mathrm{l}$; normal value for age $150-450 \mathrm{mg} / \mathrm{l}$ ), as was lactate $(1690 \mu \mathrm{mol} / 1$; normal range $1200-1600 \mu \mathrm{mol} / \mathrm{l})$. The concentration of glucose was normal. There was no clinical or laboratory evidence for endocrinological, immunological, and chronic infectious diseases, vitamin deficiency, or disorders caused by toxic agents.

Electroencephalography showed a generalised slowing background pattern consistent with encephalopathy. During the acute phase cerebral CT showed thin lateral ventricles indicative of cerebral oedema. Electromyography showed normal results. Electrocardiography showed signs of left ventricle hypertrophy and repolarisation disturbances. Two years later the results of EEG, cerebral $\mathrm{CT}$, and ECG were normal.

\section{Diagnostic investigations}

CLINICAL CHEMICAL ASPECTS

After the patient had made a complete recovery, biochemical studies were performed to determine the aetiology of the rhabdomyolysis. The activity of carnitine palmitoyltransferase I and II in leucocytes was normal. Serial measurements of carnitine in serum ${ }^{18}$ showed a concentration of non-esterified carnitine in serum fluctuating between 6 and 38 $\mu \mathrm{mol} / 1$ (table) with a mean level of $21 \mu \mathrm{mol} / 1$ (controls $>20$ (mean $38 \mu \mathrm{mol} / \mathrm{l}$ )). Organic acids were determined in urine by gas chromatography-mass spectrometry. Fast atom bombardment mass spectrometry was used to analyse the excretion profile of acylcarnitines. ${ }^{19}$ There was a moderate dicarboxylic aciduria with increased excretion of suberylglycine, with an increase in excretion on prolonged fasting. The acylcarnitine analysis showed increased excretion of almost exclusively octanoylcarnitine. The identity of these acylcarnitines was confirmed by accurate mass measurements and by linked scanning of the isobutyl esters.

Normal concentrations of amino acids were found in serum and urine.

Serum and muscle carnitine concentrations before and during carnitine treatment in the patient and controls

\begin{tabular}{|c|c|c|c|}
\hline & \multicolumn{2}{|l|}{ Patient } & \multirow{2}{*}{ Controls } \\
\hline & - Carnitine & + Carnitine & \\
\hline $\begin{array}{l}\text { Serum }(\mu \mathrm{mol} / \mathrm{l}): \\
\quad \text { Total carnitine } \\
\text { Non-esterified carnitine }\end{array}$ & $\begin{array}{r}13-43 \\
6-38\end{array}$ & $\begin{array}{l}25-78 \\
13-41\end{array}$ & $\begin{array}{l}>25 \\
>20\end{array}$ \\
\hline $\begin{array}{l}\text { Muscle }(\mu \mathrm{mol} / \mathrm{g} \text { wet weight) } \\
\text { Total carnitine } \\
\text { Non-esterified carnitine }\end{array}$ & $\begin{array}{l}0.84 \\
0.73\end{array}$ & $\begin{array}{l}0.97 \\
0.61\end{array}$ & $\begin{array}{l}2 \cdot 7-4 \cdot 6 \\
2 \cdot 2-4 \cdot 2\end{array}$ \\
\hline
\end{tabular}

\section{MORPHOLOGICAL STUDIES}

A biopsy from the vastus medialis muscle was taken one month after the rhabdomyolytic period. Only $20 \%$ of the fibres were type I (normal 35-50\%). In semithin toluidine stained Epon sections there was an increased amount of lipid droplets between the myofibrils, mainly in type I fibres. Electron microscopy showed numerous lipid droplets as well as local glycogen accumulation. Morphometric studies ${ }^{20}$ showed that the volume density of lipid droplets $\left(\mathrm{V}_{\mathrm{li}}\right)$ : volume density of the myofibrils $\left(\mathrm{V}_{\mathrm{mf}}\right)$ ratio was twice the control mean $\left(\mathrm{V}_{\mathrm{li}} / \mathrm{V}_{\mathrm{mf}}\right.$ patient 0.87 (SEM $0 \cdot 15$ ), controls 0.36 (SEM 0.07)).

\section{BIOCHEMICAL ASPECTS}

Concentrations of total and non-esterified carnitine in muscle tissue ${ }^{18}$ were about $25 \%$ of control values (table). The activities of carnitine palmitoyltransferase I and II, citrate synthase, creatine kinase, cytochrome $c$ oxidase, palmitoyl-CoA synthetase, and succinate dehydrogenase were normal in skeletal muscle. ${ }^{21}$

The oxidation rates of radiolabelled palmitate, octanoate, butyrate, and pyruvate by intact cultured fibroblasts were determined according to Veerkamp et al. ${ }^{22}$ The rate of octanoate was diminished to $5 \%$ of the control mean $(0.11 v 2.4(\mathrm{SD} 0.9))$ nmol.h $^{-1}$. $\mathrm{mg}^{-1}$ protein. MCAD deficiency was established in fibroblast homogenate $(1.6 v 15.6$ (6.2) mU.U $\mathrm{U}^{-1}$ citrate synthase), using an electron transfer flavoprotein linked assay. ${ }^{23}$ The activities of short chain and long chain acyl$\mathrm{CoA}$ dehydrogenases were normal. In a $600 \mathrm{~g}$ supernatant of a frozen skeletal muscle specimen, with phenazine methosulphate and dichlorophenolindophenol as electron acceptor, ${ }^{24} \mathrm{MCAD}$ activity was not above the detection limit.

\section{MOLECULAR BIOLOGICAL ASPECTS}

Genomic DNA studies were performed on muscle tissue and skin fibroblasts. The DNA was extracted from cultured skin fibroblasts and skeletal muscle homogenate; $2 \mu \mathrm{g}$ was used to amplify an $87 \mathrm{bp}$ region using the polymerase chain reaction (PCR). The oligonucleotide primers used create a restriction site for NcoI in the mutant fragment. ${ }^{25}$ After an initial eight minute denaturation step at $94^{\circ} \mathrm{C}$, the PCR reaction was repeated for 30 cycles (one minute denaturation at $94^{\circ} \mathrm{C}$; two minutes annealing at $50^{\circ} \mathrm{C}$; and three minutes extension at $72^{\circ} \mathrm{C}$; the final extension was for eight minutes). The $87 \mathrm{bp}$ PCR product was precipitated and resuspended in $20 \mu \mathrm{l}$ of $\mathrm{H}_{2} \mathrm{O}$. A $10 \mu \mathrm{l}$ aliquot was digested with $5 \mathrm{U}$ of $\mathrm{NcoI}$ at $37^{\circ} \mathrm{C}$ for two hours. The original PCR fragment and the products of the restriction digest were treated by electrophoresis on a $3 \%$ agarose gel containing ethidium bromide.

Digestion with NcoI of the amplified DNA from the patient's fibroblasts and muscle showed only 61 and $26 \mathrm{bp}$ fragments and no $87 \mathrm{bp}$ fragment (fig 1, lanes 8 and 10). Therefore the patient was apparently homozygous for the 985 point mutation. 


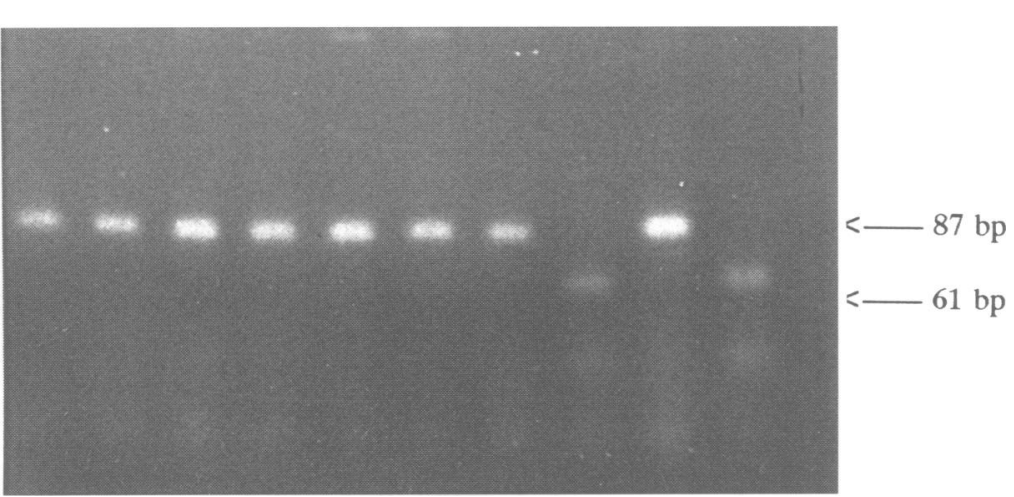

Figure 1 Electrophoretic pattern of the 87 bp fragments and their NcoI digestion products after PCR amplification of muscle and fibroblast DNA from patient and controls. The 61 bp NcoI digestion product is distinct, the 26 bp product is hardly visible. Lanes 1-6 = control muscle; lanes 7-8 = patient's fibroblasts; lanes 9-10 = patient's muscle; odd numbers = original PCR fragments; even numbers = digested PCR products.

The synthesis and stability of the MCAD protein was estimated in cultured skin fibroblasts. The normal medium for growing cells was Eagle's minimum essential medium (EMEM) supplemented with $10 \%$ fetal calf serum (FCS) and antibiotics. For $\left[{ }^{35} \mathrm{~S}\right]$ methionine incorporation experiments medium was removed from confluent monolayers. Each dish (area $65 \mathrm{~cm}^{2}$ ) was washed twice with phosphate buffered saline (PBS) and incubated at $37^{\circ} \mathrm{C}$ for two hours with 5 $\mathrm{ml}$ labelling medium (E-MEM without methionine but with $10 \%$ FCS). This medium was replaced by $5 \mathrm{ml}$ of fresh labelling medium containing $\mathrm{L}-\left[{ }^{35} \mathrm{~S}\right]$ methionine $(100 \mu \mathrm{Ci})$. After incubation for one hour at $37^{\circ} \mathrm{C}$ the medium was removed. In some experiments the degradation of the synthesised protein was studied by incubating the cells for another six or 17 hours in normal medium with added unlabelled methionine. The cell layers were rinsed twice with PBS containing $2 \%$ unlabelled methionine and solubilised by the addition of $1 \mathrm{ml}$ NETS medium (150 mM NaCl, $10 \mathrm{mM}$ EDTA, $0.5 \%$ Triton $\mathrm{X}-100,0.25 \%$ sodium dodecylsulphate, and $2 \%$ unlabelled methionine, $\mathrm{pH}$

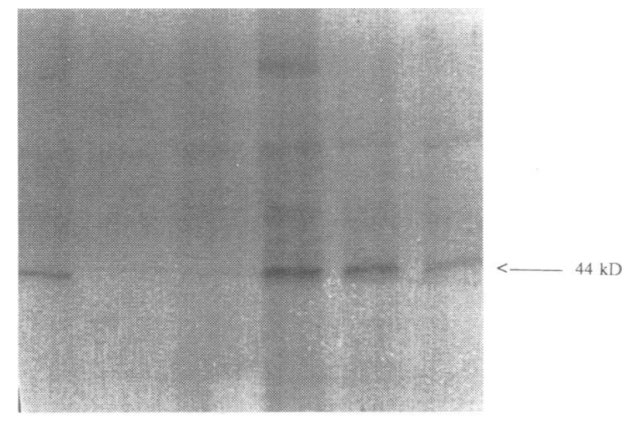

Figure 2 Gel electrophoretic pattern of the MCAD protein synthesised in fibroblasts from patient and control. Lanes 1, 2 and $3=$ patient; lanes 4, 5, and $6=$ control; lanes 1 and $4=M C A D$ protein synthesised in one hour; lanes 2 and $5=M C A D$ protein synthesised in one hour, followed by six hours incubation in unlabelled medium; lanes 3 and $6=M C A D$ protein synthesised in one hour, followed by 17 hours incubation in unlabelled medium.
$7 \cdot 4)$. The cell extract was centrifuged for one hour at $50000 \mathrm{~g}$. The supernatant was mixed with antiserum raised against pig liver $\mathrm{MCAD},{ }^{26}$ and incubated overnight at $4^{\circ} \mathrm{C}$. The antigen-antibody complex was precipitated by adding $100 \mu \mathrm{l}$ of Staphylococcus aureus cell suspension, followed by centrifugation ( 10 minutes at $1700 \mathrm{~g}$ ). The pellet was washed four times with $2 \mathrm{ml}$ of buffer containing $150 \mathrm{ml} \mathrm{NaCl}, 10 \mathrm{mM}$ Tris- $\mathrm{HCl}, 1 \%$ Triton $\mathrm{X}-100,1 \%$ deoxycholate, and $0 \cdot 1 \%$ sodium dodecylsulphate, $\mathrm{pH} 7 \cdot 2$. The washed immunoprecipitate was solubilised by boiling (five minutes) in $50 \mu \mathrm{l}$ of a denaturating buffer containing $8 \%$ mercaptoethanol and $0.003 \%$ bromophenol blue. After 10 minutes centrifugation at $6000 \mathrm{~g}$ the supernatant was subjected to SDS-PAGE electrophoresis according to Laemmli, ${ }^{27}$ with $12 \%$ gels. The gels were treated for fluorography with Autofluor (Amersham, Buckinghamshire, UK), dried, and fluorographed according to the supplier's instructions.

Figure 2 shows the representative MCAD synthesis pattern. The MCAD protein was synthesised by the patient's fibroblasts at a normal rate (lane 1 ). The rapid disappearance of the protein incorporated radiolabelled methionine suggests a reduced stability of the protein (lanes 2 and 3 ). This is likely due to the impaired ability of the mutant $44 \mathrm{kDa}$ monomers to form a stable tetramer. ${ }^{28-30}$

\section{Carnitine treatment}

The patient was treated with $8 \mathrm{~g}$ DL-carnitine daily for nine months. During the first month of carnitine supplementation the patient noticed an improvement in his general condition. Total carnitine concentrations in serum increased to near normal values and became more constant. The concentration of carnitine in muscle after nine months of carnitine treatment had not increased (table), and lipid accumulation between the myofibrils had not disappeared. Supplementation was stopped as no objective improvement was seen.

Supplementation of $6 \mathrm{~g} /$ day riboflavin (the precursor of the flavin moiety of MCAD) had no beneficial effect.

\section{Physiological tests}

These tests were performed after informed consent of the patient.

\section{FASTING STUDIES}

Prolonged fasting studies were performed before the diagnosis of MCAD deficiency was established. The blood concentrations of the most important metabolites were determined before and after the patient had been treated with carnitine for 40 days. Figure 3 shows the results. The concentration of non-esterified fatty acids and ketone bodies increased during fasting, whereas the ratio of ketone bodies:non-esterified fatty acids declined to 0.33 at 48 hours without carnitine supplementation. Glucose concentrations remained above $4.2 \mathrm{mmol} / 1$ for 48 hours, but declined 
Figure 3 Concentrations of lactate, ketone bodies, non-esterified (free) fatty acids, and esterified and non-esterified carnitine in patient's blood during prolonged fasting. Left: without carnitine supplementation; Right: during carnitine supplementation ( $8 \mathrm{~g} \mathrm{DL}$ carnitine).
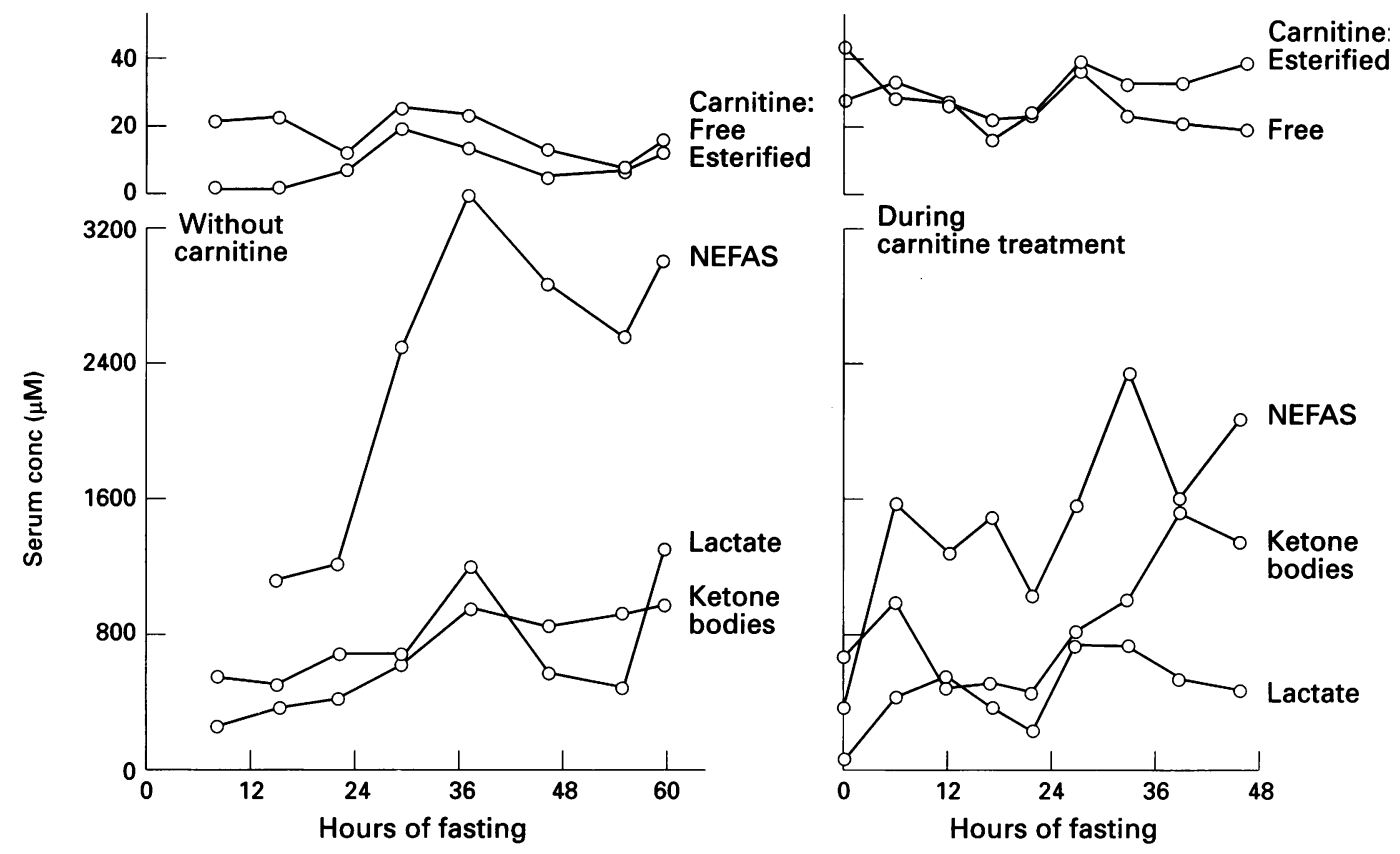

at 55 hours to $3.0 \mathrm{mmol} / \mathrm{l}$. A more pronounced ketogenic response to fasting was found during carnitine treatment, whereas the non-esterified fatty acid concentration remained normal. The ketone bodies:nonesterified fatty acids ratio was 0.68 after a 48 hour fast. Glucose concentrations were maintained at $4.4 \mathrm{mmol} / \mathrm{l}$. Apparently, the low carnitine concentrations had some pathophysiological consequences besides the MCAD deficiency.

\section{EXERCISE TESTS}

The patient participated in two prolonged exercise tests $^{31}$ (again before the diagnosis was made), one before and one during carnitine treatment. The patient became confused and experienced myalgia and nausea at the end of the exercise test without carnitine. The normal glucose concentration could no longer be maintained and lactate and ammonia concentrations showed a pronounced rise. During carnitine treatment he performed the prolonged exercise test with only slight myalgia and felt well after finishing. The glucose, lactate, and ammonia concentrations did not become abnormal on this occasion.

\section{Discussion}

Since 1982 MCAD deficiency has been recognised in young children with episodic illness resembling Reye syndrome, provoked by viral illness, fever, and fasting. ${ }^{1232-34}$ The first episode is often before the age of 2 years. ${ }^{1235}$ The patients show a broad range of clinical presentation-namely, intolerance to fasting, episodic vomiting, lethargy, altered consciousness, and even coma. The outcome may be severe and fatal, although complete recovery has also been described. ${ }^{16}$ Dependent on the degree of involvement of the liver, heart, and skeletal muscle, the clinical features may range from recurrent episodes of hypogly- caemia to progressive muscle weakness and myalgia. Serum creatine kinase may be moderately increased. In many patients the muscular symptoms are not prominent, but some have symptoms of muscle weakness.

Techniques such as gas chromatographymass spectrometry and fast atom bombardment mass spectrometry make it possible to establish this metabolic disorder easily. ${ }^{1936}$ Recently the value of measuring octanoylcarnitine in plasma from patients suspected to have MCAD deficiency has been stressed. ${ }^{15}$ Deficiency of MCAD has been associated with a molecular lesion involving an $A$ to $G$ nucleotide replacement at position 985 of the MCAD coding sequence, ${ }^{17}$ resulting in replacement of lysine ${ }^{329}$ by glutamic acid. ${ }^{30}$ Although the prevalence of this mutation is high in patients deficient in MCAD, this approach is not yet appropriate to diagnose all patients with MCAD deficiency. ${ }^{30} 37$

Until now only one asymptomatic adult with MCAD deficiency has been described, ${ }^{16}$ but his genotype was not established. We report the first patient with the MCAD point mutation at nucleotide position 985 whose clinical symptoms appeared at an adult age, whose medical history did not include muscle problems during childhood, and who did not have a positive family history. The clinical presentation of MCAD deficiency in this patient consisted of acute rhabdomyolysis and transient encephalopathy, provoked by prolonged exertion and fasting. Hitherto, rhabdomyolysis has not been associated with MCAD deficiency, although it has recently been described in several other defects of fatty acid oxidation. ${ }^{8-10}$ Fatty acids are important substrates for skeletal muscle, especially during prolonged exercise and fasting. The decreased oxidative capacity of muscle tissue can result in a moderate accumulation of lipid droplets.

The transient encephalopathy in the pre- 
sent patient may be considered as a complication of rhabdomyolysis or a diminished supply of ketone bodies to the brain. The metabolism of the brain depends on glucose oxidation and, during fasting, on the oxidation of ketone bodies. Fatty acids are hardly metabolised by brain tissue. When the excess of medium chain fatty acids can no longer be metabolised by $\beta$-oxidation, as occurs in MCAD deficiency, ketogenesis becomes impaired and $\omega$ oxidation takes place. The impaired oxidation of octanoate may also have contributed to the development of encephalopathic symptoms. Octanoate disturbs the excretion of organic anionic compounds and mitochondrial functioning, especially in the choroid plexus. ${ }^{38}$ It also induces epileptic and encephalopathic symptoms. Carnitine supplementation can stimulate detoxification of octanoate by esterification, after which octanoylcarnitine is rapidly excreted.

The main dietary advice for patients with disorders of fatty acid oxidation is to have an adequate carbohydrate intake at regular times. ${ }^{14}$ The supplementation of this patient's diet with carnitine may have improved exercise tolerance and protected against the metabolic consequences of prolonged fasting.

It is remarkable that in our patient, with the aberrant clinical symptoms, the same point mutation and the same biochemical features have been found as in the far more severe cases of MCAD deficiency. Our patient shows the mutation in both alleles. The question arises as to which factor(s) determine this clinical heterogeneity. It has been shown that the 985 point mutation results in a diminished concentration of MCAD protein as a consequence of an enhanced degradation rate of the protein. ${ }^{29} 39$ Recently, other point mutations, some of them being localised on exon 11 like the 985 mutation, have been found especially in compound heterozygotes. ${ }^{303740-42}$ Possibly environmental factors or the relative activity of the other enzymes of $\beta$-oxidation play a part in determining the phenotype in patients deficient in MCAD. It is important to realise that in adults with unexplained rhabdomyolysis and acute encephalopathy a diagnosis of MCAD deficiency, or other disturbances in fatty acid oxidation, should be considered.

This investigation is part of the research programme Disorders of the Neuromuscular System of the University of Nijmegen. We are indebted to Professor J H Veerkamp (Department of Biochemistry, University of Nijmegen), Dr H J Ter Laak (Institute of Neurology, University of Nijmegen), Professor A M Stadhouders (Department of Cell Biology, University of Nijmegen), Professor R C A Sengers, Professor J M F Trijbels, Pediatrics, University of Nijmegen), and Dr S DiDonato (National Institute of Neurology "C Besta", Milan) for investi(National Institute of Neurology "C Besta", Milan) for investigations, discussion, and advice. R A C is grateful to Drs K N matography-mass spectroscopy and fast atom bombardmentmass spectrometry studies.

1 Rowland LP. Myoglobinuria. Can f Neurol Sci 1984, 11:1-13.

2 Poels PJE, Gabreëls FJM. Rhabdomyolysis: a review of the literature. Clin Neurol Neurosurg 1993;95:175-92.

3 Penn AS. Myoglobinuria. In: Engel AG, Banker BO, eds Myology. Vol 2. New York: McGraw-Hill 1986:1785 805.

4 Tonin P, Lewis P, Servidei S, DiMauro S. Metabolic causes of myoglobinuria. Ann Neurol 1990;27:181-5.

5 Prockop LD, Engel WK, Shug AL. Nearly fatal muscle carnitine deficiency with full recovery after replacement therapy. Neurology 1983;33:1629-31.

6 Carrier HN, Berthillier G. Carnitine levels in normal children and adults and in patients with diseased muscle. Muscle Nerve 1980;3:326-34.

7 Engel AG, Rebouche CJ. Pathogenetic mechanisms in human carnitine deficiency syndromes. In: Schotland DL, ed. Disorders of the motor unit. New York: Wiley and Sons, 1982:643-56.

8 Dionisi Vici C, Burlina AB, Bertini E, et al. Progressive neuropathy and recurrent myoglobinuria in a child with long-chain 3-hydroxyacyl-coenzyme A dehydrogenase deficiency. F Pediatr 1991;118:744-6.

9 Jackson S, Singh Kler R, Bartlett K, et al. Combined enzyme defect of mitochondrial fatty acid oxidation. f Clin Invest 1992;90:1219-25.

10 Ogilvie I, Pourfarzam M, Jackson S, Stockdale C, Bartlett $\mathrm{K}$, Turnbull $\mathrm{DM}$. Very long-chain acyl coenzyme A dehydrogenase deficiency presenting with exerciseinduced myoglobinuria. Neurology 1994;44:467-73.

11 Engel AG. Carnitine deficiency syndromes and lipid storage myopathies. In: Engel AG, Banker BQ, eds. Myology. Vol 2. New York: McGraw-Hill, 1986:166395.

12 Rhead WJ. Inborn errors of fatty acid oxidation in man. Clin Biochem 1991;24:319-29.

13 Coates PM, Hale DE, Stanley CA, Corkey BE, Cortner JA. Genetic deficiency of medium-chain acyl coenzyme A dehydrogenase: studies in cultured skin fibroblasts and peripheral mononuclear leukocytes. Pediatr Res 1985;19: peripheral

14 Roe CR, Millington DS, Maltby DA, Bohan TP, Kahler SG, Chalmers RA. Diagnostic and therapeutic implications of medium chain acylcarnitines in the mediumchain acyl-CoA dehydrogenase deficiency. Pediatr Res 1985;19:459-66.

15 Van Hove JLK, Zhang W, Kahler SG, et al. Medium-chain acyl-CoA dehydrogenase (MCAD) deficiency: diagnosis by acylcarnitine analysis in blood. Am $\mathcal{F}$ Hum Genet 1993;52:958-66.

16 Duran M, Hofkamp M, Rhead W, Saudubray JM, Wadman SK. Sudden child death and "healthy" affected family members with medium-chain acyl-coenzyme A dehydrogenase deficiency. Pediatrics 1986;78:1052-7.

17 Matsubara Y, Narisawa K, Miyabayashi S, Tada K, Coates PM. Molecular lesion in patients with mediumchain acyl-CoA dehydrogenase deficiency. Lancet 1990;335:1589.

18 Parvin R, Pande SV. Microdetermination of (-)carnitine and carnitine acetyltransferase activity. Anal Biochem 1977;79:190-201.

19 Cheng KN, Tracey BM, Rosanskiewicz J, Chalmers RA. Characterisation of acylcarnitines as their isobutyl ester derivatives using fast atom bombardment mass spectrometry and constant neutral loss scan. Biomedical Mass Spectrometry 1989;18:668-72.

20 Hoppeler H, Lüthe P, Claasen $\mathrm{H}$, Weibel ER, Howald $\mathrm{H}$. The ultrastructure of the normal human skeletal muscle. A morphometric analysis on untrained men, women and well-trained orienteers. Pflügers Arch 1973;344:217-32.

21 Scholte HR, Busch HFM, Luyt-Houwen IEM, Vaandrager-Verduin MHM, Przyrembel H, Arts WFM. Defects in oxidative phosphorylation; biochemical investigations in skeletal muscle and expression of the lesion in tigations in skeletal muscle and expression of the lesion in
other cells. F Inherit Metab Dis 1987;10(suppl 1):81-97.

22 Veerkamp JH, Van Moerkerk HTB, Bakkeren JAJM. An accurate and sensitive assay of $\left[{ }^{14} \mathrm{C}\right]$ octanoate oxidation and its application on tissue homogenates and fibroand its application on tissue homogenates
blasts. Biochim Biophys Acta 1986;876:133-7.

23 Frerman FE, Goodman SI. Fluorometric assay of acylCoA dehydrogenases in normal and mutant human fibroblasts. Biochem Med 1985;33:38-44

24 Rhead W, Amendt BA, Fritchman KS, Felts SJ. Dicarboxylic aciduria: deficient $\left[1-{ }^{14} \mathrm{C}\right]$ octanoate oxidation and medium chain acyl-CoA dehydrogenase in fibroblasts. Science 1983;221:73-5.

25 Yokota I, Indo Y, Coates PM, Tanaka K. Molecular basis of medium-chain acyl-coenzyme A dehydrogenase deficiency; an $A$ to $G$ transition at position 985 that causes a lysine-304 to glutamate substitution in the mature protein is the single prevalent mutation. $f$ Clin mature protein is the sing
Invest $1990 ; 86: 1000-3$.

26 DiDonato S, Gellera C, Peluchetti D, et al. Normalization of short-chain acylcoenzyme A dehydrogenase after riboflavin treatment in a girl with multiple acylcoenzyme
A dehydrogenase-deficient myopathy. Ann Neurol 1989;

27 Laemmli UK. Cleavage of structural proteins during assembly of the head of bacteriophage T4. Nature 1970; 227:680-5.

28 Coates PM, Indo Y, Young D, Hale DE, Tanaka K. Immunochemical characterization of variant mediumchain acyl-CoA dehydrogenase in fibroblasts from patients with medium-chain acyl-CoA dehydrogenase deficiency. Pediatr Res 1992;31:34-8.

29 Jensen TG, Andresen BS, Bross P, et al. Expression of wild-type and mutant medium-chain acyl-CoA dehydrogenase (MCAD) cDNA in eucaryotic cells Biochim Biophys Acta 1992;1180:65-72.

30 Tanaka K, Yokota I, Coates PM, et al. Mutations in the medium chain acyl-CoA dehydrogenase (MCAD) gene. Human Mutation 1992;1:271-9.

31 Braakhekke JP, Stegeman DF, Joosten EMG. Increase in 
median power frequency of the myoelectric signal in pathological fatig

32 Kolvraa S, Gregersen N, Christensen E, Hobolth N. In vitro fibroblast studies in a patient with $\mathrm{C}_{6}-\mathrm{C}_{10}$-dicarvitro fibroblast studies in a patient with $\mathrm{C}_{6}-\mathrm{C}_{10}$-dicar boxylic aciduria: evidence for a defect in general acyl-

33 Stanley $C$, Hale DE, Coates PM, et al. Medium-chain acyl-CoA dehydrogenase deficiency in children with non-ketotic hypoglycemis and low carnitine levels. Pediatr Res 1983;17:877-884.

34 Divry $\mathrm{P}$, David $\mathrm{M}$, Gregersen $\mathrm{N}$, et al. Dicarboxyli aciduria due to medium-chain acyl CoA dehydrogenas defect; a cause of hypoglycemia in childhood. Acta Paediatr Scand 1983;72:943-9.

35 Iafolla AK, Thompson RJ Jr, Roe CR. Medium-chain acyl-coenzyme A dehydrogenase deficiency: clinical acyl-co in 120 affected children. F Pediatr 1994;124: course in

36 Duran M, Mitchell G, de Klerk JBC, et al. Octanoic acidemia and octanoylcarnitine excretion with dicarboxylic aciduria due to a defective oxidation of mediumchain faty acids. $₹$ Pediatr 1985;107:397-403.

37 Yokota I, Cotes PM, Hale DE, Rinaldo P, Tanaka K Molecular survey of a prevalent mutation, ${ }^{985} \mathrm{~A}-\mathrm{to}-\mathrm{G}$ transition, and identification of five infrequent mutations in the medium-chain acyl-CoA dehydrogenase (MCAD) gene in 55 patients with MCAD deficiency. $\mathrm{Am}$ f Hum Genet 1991;49:1280-91.

$38 \mathrm{Kim}$ CS, Dorgan DR, Roe CR. L-carnitine: therapeutic strategy for metabolic encephalopathy. Brain Res 1984, 310:149-53.

39 Whelan AJ, Strauss AW, Hale DE, Mendelsohn NJ, Kelly DP. Expression and characterization of human mutan DP. Expression and characterization of human mutan glutamic acid a medium-chain acyl-coenzyme A dehydrogenas

40 Kelly DP, Hale DE, Rutledge SL, et al. Molecular basis of inherited medium-chain acyl-CoA dehydrogenase deficiency causing sudden child death. $₹$ Inherit Metab Dis 1992;15:171-80.

41 Zhang Z, Kølvraa S, Zhou Y, et al. Three RFLPs defining a haplotype associated with the common mutation in human medium-chain acyl-CoA dehydrogenase (MCAD) deficiency occur in Alu repeats. Am $\mathscr{f} \mathrm{Hum}$ Genet 1993;52:1111-21.

42 Andresen BS, Bross P, Jensen TG, et al. A rare diseaseassociated mutation in the medium-chain acyl-CoA dehydrogenase (MCAD) gene changes a conserved arginine, previously shown to be functionally essential in short-chain acyl-CoA dehydrogenase (SCAD). Am $\mathcal{f}$ short-chain acyl-CoA dehydr 